\title{
Psychological distress and quality of life among female stress urinary incontinence patients pre and post non-invasive laser therapy
}

\author{
Safaa Mostafa Abdeen ${ }^{1,}$ Hassan Ali Abdelhaleem Ahmed ${ }^{2}$ \& Sanaa Mostafa Khalifa ${ }^{3}$ \\ 1. Lecturer of Psychiatric- Mental Health Nursing, Faculty of Nursing, Sohag University-Egypt \\ 2. Lecturer of Urology, Faculty of Medicine, Sohag University- Egypt \\ 3. Lecturer of Psychiatric- Mental Health Nursing, Faculty of Nursing, Sohag University-Egypt
}

\begin{abstract}
Background: Psychological morbidity is common in women with urinary incontinence and is likely to result directly from the impact on quality of life. The study aimed to: - evaluate the psychological distress and quality of life among female stress urinary incontinence patients pre and post non-invasive laser therapy \&assess the efficacy of a novel minimally invasive non-ablative laser treatment for female SUI. (Stress Urinary Incontinence) Design: This is prospective non randomized study. Sample: the study was carried out at Urology Department, Sohag University Hospital on $10 \%$ (32 patients) of the female patient. Tools: - International Consultation on Incontinence Questionnaire - Urinary Incontinence Short Form (ICIQ-UI SF), Kessler Psychological Distress Scale (K10), and (Incontinence Quality of Life) I-QOL. Results: - The majority of the participant have moderate and severe psychological distress. There were statistically significant difference between levels of psychological distress at pre and post Laser therapy among studied patient; also, quality of life domains at pre, and post laser therapy among studied patient. Conclusions: Stress urinary incontinence can cause psychological distress for majority of patients and also, have a negative impact on their quality of life. Recommendations: - psychological intervention beside laser therapy will be improve psychological distress and QOL among SUI.
\end{abstract}

\section{Keywords: SUI, Non-invasive laser therapy, Psychological Distress \& QOL}

\section{Introduction}

Urinary incontinence (UI) is a common issue, especially among women. Urinary incontinence was recorded by 13.6 percent of women in a populationbased cross-sectional study (Irwin, 2006). The World Health Organization (WHO) has identified urinary incontinence as one of the most pressing health issues today. According to statistics, more than a third of women in their forties and fifties have signs of the condition, and more than half of them have stress urinary incontinence (Barber et al., 2005). Urinary incontinence affects 16 percent of women under the age of 30 and 29 percent of women between the ages of 30 and 60 (Hunskaar et al., 2003).

The main SUI (Stress Urinary Incontinence) Pelvic floor disorders, ageing, pregnancy, vaginal birth, smoking, obesity, diabetes, perineum injury, inadequate control of the urethral constrictor muscle, and heavy physical labor as well as menopause, are all risk factors (Patel, \&Thomason., 2006).

SUI must be detected and treated not only to prevent medical complications, but also to control the psychological and social effects of the disease. SUI can lead to feelings of guilt, low self-esteem and social withdrawal. Outpatients have also characterized their experience with SUI as humiliating and causing major disruption in their daily lives. Female patients with SUI may be In this respect, (Castro et al., 2015 \& MacLennan concerned about not having easy access to a toilet and fearing a public urinary accident. Depression and anxiety symptoms can be linked to SUI for these reasons (Hillary et al, .2002).

SUI had an effect on one's lifestyle, restricting one's ability to perform certain everyday activities. It also necessitated continuous security (wearing of pads) in order to preserve body hygiene, overcoming potential difficulties in relationships with family and friends, changing sexual behaviour, and, in some cases, changing one's occupation (Hägglund et al., 2004).

SUI has a negative effect on the health-related quality of life of women. The fear of urine leakage prevents some women from participating in several activities with their family and friends. Urine loss can also happen during sexual intercourse, which can be very upsetting (Temml et al., 2000).

Many facets of everyday life can be negatively impacted by urinary incontinence. In women with urinary incontinence, psychological morbidity is normal, and it is likely to result directly from the effect on quality of life. These women also experience low self-esteem, feelings of guilt and embarrassment and a sense of being unattractive to others. Each of these is a hindrance to psychological health (Charalambous, 2009). Many studies founded that women with incontinence have psychological problems (Norton et al., 1990).

et al., 2000) reported that, UI has a major impact on 
people's quality of life in terms of physical, social, economic and psychological factors. The effect of UI on quality of life is determined by the degree and quantity of leakage as well as the woman's experience with the symptoms (Gil et al., 2009).

SUI can be treated with a variety of non-surgical and surgical options. Behavioral improvements such as weight loss, smoking abstinence, pelvic floor muscle exercise (PFMT), electrical stimulation, weighted vaginal cones and drug therapy are also non-surgical solutions for reducing stress incontinence (Gustaf, 2015). Surgical treatments for SUI are more successful than non-surgical interventions, but they may have side effects and complications including bleeding, bladder perforation, urethral injury, infection and genital pain (Novara. et al, .2010).

In terms of biochemical, ablative and thermal effects, lasers have a long track record in medicine. In contrast to the pretreatment condition, thermal energy from the laser source induces neocolagenesis as well as immediate tightening of collagen fibrils by twothirds of their length. This can be accomplished with a non-ablative Er: YAG laser vaginal tightening treatment that uses photo thermal laser-mucosa tissue contact. (Thomsen, 1991).

\section{Significance of the study:}

Involuntary urinary loss has a high prevalence and harmful effects. Social isolation and psychological distress are often reported as effects. Indeed, it appears that SUI has the ability to negatively impact social and emotional well-being (Fultz \& Herzog, 2001). So, the present study work to explore this point. (El-Azab S ET AL.,n 2007) reported that UI is quite common in Egypt and prevalence rates are higher when compared to other reports.

\section{Aim of the study:}

The study aimed to:

- Evaluate the psychological distress and quality of life among female stress urinary incontinence patients pre and post non-invasive laser therapy.

- Assess the efficacy of a novel minimally invasive non-ablative laser treatment for female SUI.

\section{Research question:}

1.Do the women suffer from stress urinary incontinence show different types of psychological distress according to the degree of their incontinence?

2.Do the women suffer from stress urinary incontinence also show negative differences on quality of life according to the degree of their incontinence?

3.Do the women suffer from stress urinary incontinence has effect on their lifestyle and relationships with others?

\section{Subject and Methods: Study design}

The current study is a prospective non randomized study including 32 female patient presented and referred to the Urology Department, Sohag University Hospital with non-complicated SUI in the period from the beginning of March 2019 to February 2020. The procedure with its benefits and risks was discussed with the patients and written informed consent was obtained from all patients. The study was approved from Sohag University Hospital's ethics committee.

\section{Study setting and sampling}

The study was carried out at Urology Department, Sohag University Hospital. Sample size was calculated using Power Analysis and Sample Size software program (PASS) version 15.00 for windows (2017) with the proportion of patients expected to be dry (ICIQ-UI SF score $=0$ ) after treatment as the primary outcome. All patients will be treated by a minimally - invasive, non-ablative Er: YAG laser vaginal tightening procedure utilizing photo thermal laser-mucosa tissue interaction. The proportion of patients expected to be dry (ICIQ-UI SF score =0) after treatment was considered to be $30 \%$ as suggested by RCT done by (Mija Blaganjea et al 2018). A sample of 32 patients is needed to achieve $80 \%$ power ( $1-\beta$ or the probability of rejecting the null hypothesis when it is false) with a significance level of 5\% ( $\alpha$ or the probability of rejecting the null hypothesis when it is true).

Tools of the study:

Three tools were used in the present study to fulfill its aim which including:

\section{Tool one:- International Consultation on Incontinence Questionnaire - Urinary Incontinence Short Form (ICIQ-UI SF Klovning et al., 2009)}

The degrees of SUI and its impact on the quality of life were assessed using the International Consultation on Incontinence Questionnaire Urinary Incontinence Short Form (ICIQ-UI SF). (Hashim et al., 2006) has been validated Arabic version of this questionnaire. Results of the ICIQ-UI SF were divided into the following four severity stages: slight (1-5), moderate (6-12), severe (13-18) and very severe (19-21), as suggested by (Klovning et al., 2009).

Full gynecological examination was done to determine the suitability of patient for the vaginal laser therapy e.g. the presence gynecological infections in addition to cough test, Pelvic Organ Prolapse (POP), vaginal mucosal atrophy and vaginal lesions were assessed. 


\section{Tool two:Kessler Psychological Distress Scale} (K10)

This scale has been developed in the original English language version by Kessler et al, (2003) and translated into Arabic version by the researcher. The purpose of the Kessler Psychological Distress Scale (K10) to measure the psychological distress based on questions about anxiety and depressive symptoms that a person has experienced in the most recent 4 week period.

This scale consist of 10 items with response options on a 5 point Likert scale with the following manner:-

$1=$ Occurring the symptoms none of the time.

$2=$ Occurring the symptoms a little of the time.

$3=$ Occurring the symptoms some of the time.

$4=$ Occurring the symptoms most of the time.

$5=$ Occurring the symptoms all of the time.

Scores will range from 10 to 50. Low scores indicate low level of psychological distress and high scores indicate high level of psychological distress.

- Score under 20 likely to be well or healthy women.

- Score 20-24 likely to have a mild psychological distress.

- Score 25-29 likely to have moderate psychological distress.

- Score 30 and over likely to have a severe psychological distress.

This questionnaire was translated into Arabic version by the researcher and revises by three professors in psychiatryto suit the studied subjects' culture. Reliability of this questionnaire was done by using Cronbach's Alpha. It was 0.775.

Tool three:Incontinence Quality of Life questionnaire (I-QOL) (Kobachi et al., 2005).

This questionnaire has been developed in the original English language version by (Kobachi et al., 2005). The (I-QOL) contains 22 items designed to assess the health related quality of life impact of urinary incontinence. Is divided into 3 domains.

- 8 items assessing the physical impact domain including questions number $2,3,4,6,10,11,20$ and 21.

- 9 items assessing the psychological impact domain including questions number $5,7,9,12$, $13,15,16,17$ and 19 .

- 5 items assessing the social embarrassment domain including questions number 1,8,14,18,22 .

Scores are calculated for each domain and total summary score can be calculated from all 22 items.

This questionnaire with response options on a 5 point Likert scale as the following: None of the time $=5, \mathrm{~A}$ little of the time $=4$, Some of the time $=3$, Most of the time $=2$, and All of the time $=1$.

Higher I-QOL scores $\rightarrow$ indicates better levels of
QOL.

This questionnaire was translated into Arabic version by the researcher and revise by three professors in psychiatry to suit the studied subjects' culture. Reliability of this questionnaire was done by using Cronbach's Alpha. It was 0.772

\section{Methods of data collection: \\ Tool validity:}

Content validity of the tools was determined through an extensive review of literature about the ' Psychological distress and quality of life among female stress urinary incontinence patients pre and post non-invasive laser therapy'

The content of the data collection tools was submitted to a panel of five experts in the psychiatry and psychiatric nursing field with more than ten years of experience in the field. Modifications of the tools were done according to the panel judgment on the clarity of sentences, appropriateness of the content, sequence of items, and accuracy of scoring and recording of the items.

Pilot study:

It was carried out on $10 \%$ of the female patient presented and referred to the Urology Department, Sohag University Hospital with non-complicated SUI, for modification clarification and estimation of the time needed for filling the study tools, and testing the feasibility of the research process. Those who shared in the pilot study were excluded from the study sample.

\section{Methods for data collection: -}

- Before starting this study, formal administrative approval was taken from authorities in the setting. An official permissions was obtained from the director of Sohag University Hospital also, the head of Urology Department.

- After obtaining the written permission, a written informed consent was obtained from each patient was participated in the study before the noninvasive laser therapy.

- Oral permission from the patients for data collection, each patient was interviewed face to face by the researchers and all tools of the study were distributed.

1. The researcher read each question for the participants carefully and asked them to answer the questions honestly. Also, they were asked to circle the answer that best described them the majority of the time.

2. The researchers were available for more clarification whenever needed. Once the participants completed the questionnaire, the 
researchers collected from the participants.

3. All patients underwent a detailed medical history including - the duration and the severity of incontinence episodes, number of pads usage, menstrual \& obstetric history, medical \& drug history and previous treatment modalities.

- At the pre treatment phase ( before using Er:YAG Laser therapy) the degree of SUI, its impact on the psychological status of the patient and quality of life, were assessed using the International Consultation on Incontinence Questionnaire - Urinary Incontinence Short Form (ICIQ-UI SF), Kessler Psychological Distress Scale (K10), and Incontinence Quality of Life (I-QOL) questionnaire.

- Post treatment procedure phase, all patients reevaluated again by the previous tools after one month.

- According to the operative procedure at follow up phase all patients were reevaluated again at 1, 3, 6 months and 1 year by using the International Consultation on Incontinence Questionnaire - Urinary Incontinence Short Form (ICIQ-UI SF) to evaluate the degree of SUI and be assured the efficacy of the treatement.

\section{Ethical consideration:}

The researchers explained the study's purpose and benefits to the patients. Patients were told that participation in the research is entirely voluntary also, have the ethical right to participate or decline. It was also stressed that their answers are private, and that they have the right to withdraw from the study at any time without explanation. All data collection procedures were strictly adhered to in terms of privacy and confidentiality.

\section{Statistical analysis:}

The data obtained were reviewed, prepared for computer entry, coded, and scored, then analyzed and tabulated. Data entry and analysis were done using SPSS (statistical software package) version 17.0. The results were presented as means, standard deviations, and percentage distributions. A person's correlation is used for the numeric variable. N.s $\mathrm{P}>0.05$ is no significant, and $\mathrm{P} \leq 0.05$ as a cutoff for significance.

\section{Results:}

Table (1): Demographic data, Obstetric and gynecological history of the study participants

\begin{tabular}{|c|c|c|c|c|l|}
\hline \multicolumn{7}{|c|}{ All patients (n= 32) } \\
\hline Maximum & Minimum & IQR & Median & Mean \pm SD & \\
\hline 62 & 26 & $34.25 ; 42.75$ & 38 & $38.81 \pm 7.59$ & Age \\
\hline 29.5 & 19 & $22 ; 26$ & 24 & $23.95 \pm 2.78$ & BMI \\
\hline 8 & 2 & $3 ; 5$ & 4 & $4.09 \pm 1.53$ & Parity \\
\hline 7 & 0 & $3 ; 5$ & 4 & $3.66 \pm 1.45$ & Normal vaginal delivery \\
\hline 2 & 0 & $0 ; 0$ & 0 & $0.22 \pm 0.49$ & Abortion \\
\hline 5 & 1 & $1 ; 3$ & 2 & $2.28 \pm 1.28$ & Duration (years) \\
\hline 5 & 0 & $2 ; 4$ & 3 & $2.84 \pm 1.53$ & Number of daily pads \\
\hline \multicolumn{7}{|c|}{$63 \%(20)$} & Post menopause & Complaint \\
\hline \multicolumn{7}{|c|}{$37 \%(12)$} & SUI & \multirow{2}{*}{ POP stage } \\
\hline \multicolumn{7}{|c|}{$47 \%(15)$} & $\mathbf{1}$ & $\mathbf{2}$ \\
\hline
\end{tabular}

Data is expressed as Mean and standard deviation, Median, Inter-quartile range, Minimum and Maximum or as percentage and number. 
Table (2): Frequency of psychological distress levels at pre and post Laser therapy among studied patient $(\mathbf{n}=32)$

\begin{tabular}{|c|c|c|c|c|l|}
\hline \multirow{2}{*}{ P. value } & \multicolumn{2}{|c|}{ Post } & \multicolumn{2}{c|}{ Pre } & \multirow{2}{*}{ Levels of psychological distress } \\
\cline { 2 - 6 } & $\%$ & N. & $\%$ & N. & \multicolumn{1}{|c|}{} \\
\hline \multirow{3}{*}{0.000} & $6.2 \%$ & 2 & $0.00 \%$ & 0 & $\bullet$ Haven't any psychological distress \\
\cline { 2 - 6 } & $37.5 \%$ & 12 & $3.1 \%$ & 1 & $\bullet$ Mild psychological distress \\
\cline { 2 - 6 } & $46.9 \%$ & 15 & $46.9 \%$ & 15 & $\bullet$ Moderate psychological distress \\
\cline { 2 - 6 } & $9.4 \%$ & 3 & $50.0 \%$ & 16 & Severe psychological distress \\
\hline
\end{tabular}

* Statistical significant difference ( $p<0.05) \quad$ (Two Related samples) Wilcoxon Signed Ranks Test

Table (3): Mean scores of quality of life domains at pre, and post laser therapy among studied patient (n=32)

\begin{tabular}{|c|c|c|c|}
\hline \multirow{2}{*}{ P. value } & Post & Pre & \multirow{2}{*}{ Quality of life domains } \\
\cline { 2 - 3 } & Mean \pm SD & Mean \pm SD & The physical impact \\
\hline "0.000 & $3.227 \pm 0.279$ & $2.309 \pm 0.496$ & Psychological impact \\
\hline 0.000 & $3.632 \pm 0.247$ & $2.431 \pm 0.278$ & Social embarrassment \\
\hline "0.000 & $3.156 \pm 0.484$ & $2.231 \pm 0.374$ & Total score \\
\hline $\mathbf{0 . 0 0 0}$ & $40.015 \pm 1.01$ & $6.971 \pm 1.148$ & . \\
\hline
\end{tabular}

* Statistical significant difference $(p<0.05)$

T- Test (Paired Samples Test)

Table (4): Correlation between psychological distress and quality of life domains among studied patients $(n=32)$

\begin{tabular}{|c|c|c|c|l|}
\hline \multicolumn{3}{|c|}{ Psychological distress } & \multirow{2}{*}{ Quality of life's domains } \\
\cline { 1 - 3 } P. value & $\mathrm{R}$ & P. value & $\mathrm{R}$ & \\
\hline $\mathbf{0 . 0 0 2}$ & $\mathbf{- 0 . 5 2 1}$ & 0.466 & -0.134 & Physical domain \\
\hline 0.352 & -0.170 & ${ }^{*} \mathbf{0 . 0 0 2}$ & $-\mathbf{0 . 5 1 8}$ & Psychological domain \\
\hline 0.644 & -0.085 & 0.066 & 0.329 & Social embarrassment domain \\
\hline 0.128 & -0.274 & 0.538 & -0.113 & Total score of QOL \\
\hline
\end{tabular}

* Correlation is significant at the 0.05 level (2-tailed) Person's Correlation

Table (5): Relation between age categories and psychological distress levels among studied patients $(\mathrm{n}=32)$

\begin{tabular}{|c|c|c|c|c|c|c|c|c|c|c|}
\hline \multicolumn{10}{|c|}{ Psychological distress levels } & \multirow[b]{3}{*}{$\begin{array}{c}\text { Age } \\
\text { categories }\end{array}$} \\
\hline \multicolumn{5}{|c|}{ Post treatment } & \multicolumn{5}{|c|}{ Pre treatment } & \\
\hline P. value & $\begin{array}{c}\text { severe } \\
\text { Psychologic } \\
\text { al distress }\end{array}$ & \begin{tabular}{|} 
moderate \\
Psychologica \\
I distress
\end{tabular} & $\begin{array}{c}\text { mild } \\
\text { Psychologi } \\
\text { cal distress }\end{array}$ & healthy & P. value & $\begin{array}{c}\text { severe } \\
\text { Psycholo } \\
\text { gical } \\
\text { distress }\end{array}$ & $\begin{array}{c}\text { moderate } \\
\text { Psychological } \\
\text { distress }\end{array}$ & \begin{tabular}{|c|} 
mild \\
Psychological \\
distress
\end{tabular} & healthy & \\
\hline \multirow{3}{*}{0.185} & 0 & 4 & 7 & 2 & \multirow{3}{*}{ *0.027 } & 2 & 10 & 1 & 0 & $26-35$ \\
\hline & 3 & 9 & 4 & 0 & & 12 & 4 & 0 & 0 & $36-45$ \\
\hline & 0 & 2 & 1 & 0 & & 2 & 1 & 0 & $\overline{0}$ & $>45$ \\
\hline
\end{tabular}

* Statistical significant difference $(p<0.05)$

Chi-Square Tests

Table (6): Effect of UI type on number of sessions and post -treatment out com in the studied patient

\begin{tabular}{|c|c|c|l|}
\hline \multicolumn{3}{|c|}{ All patients $(\mathrm{n}=32)$} & \multirow{2}{*}{ Number of session } \\
\cline { 1 - 3 } $\mathbf{P}$ & Mixed UI & SUI & \\
\hline 0.036 & $2.75 \pm 1.42$ & $\mathbf{1 . 9 0} \pm \mathbf{0 . 7 2}$ & Pads after 6 months \\
\hline 0.95 & $2.00 \pm 1.91$ & $\mathbf{0 . 7 0} \pm \mathbf{0 . 9 2}$ & Daily Pad reduction \\
\hline 0.026 & $1.67 \pm 1.30$ & $3.15 \pm 3.41$ & ICIQ at 6 months \\
\hline 0.35 & $7.25 \pm 5.26$ & $9.25 \pm 2.95$ & ICIQ reduction \\
\hline
\end{tabular}

Data is expressed as Mean and standard deviation. $P$ is significant when $<0.05$.

Table (7): Comparison of pre- and post-treatment daily pads usage:

\begin{tabular}{|c|c|c|c|l|}
\hline $\mathbf{P}$ & $\mathbf{9 5 \%} \mathbf{C I}$ & Post-treatment & Pre-treatment & \multicolumn{1}{c|}{ Daily pads } \\
\hline$<\mathbf{0 . 0 0 0 1}$ & $1.17 ; 2.15$ & $1.19 \pm 1.49$ & $2.84 \pm 1.53$ & $\mathbf{6}$ months( $\mathbf{n = 3 2})$ \\
\hline$<\mathbf{0 . 0 0 0 1}$ & $1.04 ; 2.04$ & $1.08 \pm 0.83$ & $2.84 \pm 1.53$ & $\mathbf{1 2}$ months $(\mathbf{n = 2 6})$ \\
\hline
\end{tabular}

Data is expressed as Mean and standard deviation. 95\% CI: 95\% confidence interval of the mean difference.

$P$ is significant when $<0.05$. 
Table (8): Comparison of the baseline (pre-treatment) and post-treatment degree of SUI:

\begin{tabular}{|c|c|c|l|}
\hline \multirow{2}{*}{$\mathbf{P}$} & $\begin{array}{c}\text { Post-treatment } \\
(\mathbf{n = 3 2})\end{array}$ & $\begin{array}{c}\text { Baseline(pre- } \\
\text { treatment) }(\mathbf{n = 3 2})\end{array}$ & \multicolumn{1}{|c|}{ SUI } \\
\hline \multirow{4}{*}{$<\mathbf{0 . 0 0 0 1}$} & $16 \%(5)$ & $0 \%$ & None \\
\cline { 2 - 4 } & $41 \%(13)$ & $9 \%(3)$ & Mild \\
\cline { 2 - 4 } & $34 \%(11)$ & $44 \%(14)$ & Moderate \\
\cline { 2 - 4 } & $9 \%(3)$ & $47 \%(15)$ & Severe \\
\hline
\end{tabular}

Data is expressed as percentage and number. $P$ is significant when $<0.05$.

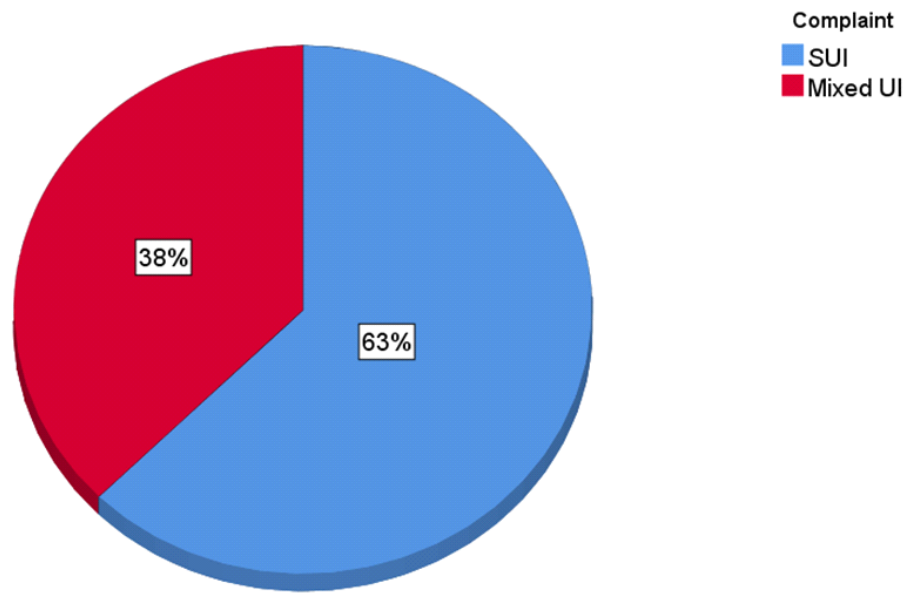

Figure (1) Type of urinary incontinence among studied patients.

Table (1): Shows Demographic data, Obstetric and gynecological history of the study participants. The current study included 32 female patients with a median age 38years (range 26-62 year) and median Body Math Index (BMI) (range 19-29.5). In addition, the median delivery per patient was 4 (ranged 2-8) with $91 \%$ of all births were vaginal deliveries. Most of the patients were in pre-menopausal state $87 \%$ (28 patients).

Table (2): As shown in regarding the frequency of psychological distress levels at pre and post Laser therapy among studied patient. At pre laser therapy , it was found that, $50 \%$ suffered from severe psychological distress and $46.9 \%$ suffered from moderate psychological distress, while at post laser therapy, only $9.4 \%$ suffered from severe psychological distress. There were statistically significant differences between pre, post laser therapy regarding levels of psychological distress $P$. value $=* 0.000$.

Table (3): Illustrates, mean scores of quality of life domains at pre, and post Laser therapy among studied patient. At pre laser therapy, the total mean score of quality of life domains was $6.971 \pm 1.148$. However, at post laser therapy, the total mean score of quality of life domains was $40.015 \pm 1.01$.

There were statistically significant differences between pre, post Laser therapy for all domains of quality of life with P. value $=* 0.000$.

Table (4): Shows correlation between psychological distress and quality of life domains among studied patients. At pre laser therapy, psychological distress was negatively significantly correlated with Psychological domain of (QOL) ( $\mathrm{r}=-0.518$ at $\mathrm{P}$. value $=* 0.002)$. At post laser therapy, psychological distress was negatively significantly correlated with Physical domain of (QOL)

( $\mathrm{r}=-0.521$ at $\mathrm{P}$. value $=* 0.002$ ).

Table (5): As showed in it was observed that, at pre Laser therapy, there were statistically significant differences between age categories and psychological distress levels P. value $=* 0.027$, while at post Laser therapy, there was statistically insignificant differences between age categories and psychological distress levels.

Table (6): Illustrated that the effect of UI type on number of sessions and post - treatment in the studied patient. It was observed that, there was no significant effect of the type of UI on the number of session needed by patients to achieve clinical improvement. However, there was a statistically significant effect of type of UI on laser therapy outcomes.

Table (7): Shows that, comparison of pre- and posttreatment daily pads usage. There was a significant reduction in the median of daily pads usage from a 
median of 3 pads per day (range 0-5) at baseline to a median of one pad per day at both 6 months and one year (range 0-3 pads per day), also there was statistical significant differences at pre- and posttreatment daily pads usage at both 6 months and one year with $\mathrm{P}$ value $(<0.0001)$.

Table (8): Shows that comparison of the baseline (pre-treatment) and post-treatment degree of SUI. At pretreatment stage $47 \%$ of patients suffered from severe SUI, while post treatment stage $9 \%$ of patients only suffered from severe stage of SUI and that means the successful of the treatment.

Figure (1): Showed the type of urinary incontinence among studied patients. This revealed that, $63 \%$ of studied patient complained of stress urinary incontinence while $37 \%$ of patient suffered from mixed urinary incontinence.

\section{Discussion:}

SUI has a negative effect on the health-related quality of life of women. (Temml et al., 2000). According to the present study, at pretreatment phase about half of women suffered from severe psychological distress, while at post treatment phase a few number of patients suffered from severe psychological distress. There were statistically significant differences between pre -post laser therapy regarding levels of psychological distress $\mathrm{P}$. value $=* 0.000$. This can interpreted as the success of the treatment procedure led to a reduction in the percentage of patient which suffered from severe psychological distress. These findings are consistent with the study of (Heidrich $\boldsymbol{\&}$ Wells, 2004) Perry et al., (2006) which showed a temporal association between urinary incontinence and measures of psychological distress.

In the current study level of distress decreased after therapy. We can interpret this as the marked improvement among urinary incontinence patients led to a reduction in the level of distress. And this findings consistent with (Dabaja et al., 2019) who founded that, distress level decreased (improved) significantly at 1-3 months post-treatment ( $\mathrm{P}<$ 0.0001). Also, (Pitsouni, et al., 2016) reported that, improved distress level one month after $\mathrm{CO} 2$ laser therapy.

The current study showed that, the total mean score of quality of life domains was increased and this indicates better level of quality of life for the participants after laser therapy improvement which is similar to the study of Tennstedt et al. 2008 showed, improvements in quality of life after stress incontinence surgery are significant and durable over 24 months.

According to correlation between psychological distress and quality of life, the present study clarified that, there were statistical significant difference between psychological domain and psychological distress and this interpreted as psychological distress increases among the younger women and among those who report the higher level of suffering.

Gil et al., (2009) reported that, level of distress scores decreased significantly in cured patients, also decrease the level of anxiety at post-treatment distress, and QOL scores increase substantially in cured patients, according to the findings. Furthermore, there was a statistically significant difference in QOL before and after treatment, which is consistent with (Behnia-Willison et al, 2019) $p$ value $<0.01$.

In the current study, there is an increase in severe psychological distress before treatment among age group 36-45 and this number decrease after treatment. Also, there is increase in moderate psychological distress before treatment among age group 26-35 and this number decrease after treatment. This is may be due to increase psychological stress, pressure and responsibilities among these age group (child bearing and raring periods). May be due to that laser therapy increase self-confidence, decrease feeling of shame in case of decrease number of pads that used to control SUI.

In the current study, the form of UI had no impact on the number of sessions needed by patients to achieve clinical improvement (63 percent SUI vs. 37 percent MUI). However, the form of UI had a statistically important impact on laser therapy outcomes. Which was similar to A prospective non-randomized research followed 175 patients with SUI (66\%) and MUI (34\%) as reported by Ogrinc et al (2015) and in follow-up for 2, 6, and 12 months. In both the SUI and MUI classes, $62 \%$ of those who posted results after a year said they had no incontinence. In patients with SUI, treatment resulted in statistically significant improvement in $77 \%$ of cases, while patients with MUI prior to treatment only improved in $34 \%$ of cases.

The findings of the current study, which used the ICIQ-UI SF Arabic version and the number of regular pads used by each patient, show that Er: YAG laser therapy in non-ablative mode effectively reduce the symptoms of SUI, even in patients with advanced stages. And the change was noticeable almost immediately after treatment, with most patients reporting it before the second treatment session, and lasting for at least 6 months. as suggested by Gasper et al (2016) who founded that the effects of a threesession laser treatment with monthly intervals last about 12 months during which time the effect fades, but can be restored and sustained by "maintenance sessions" done once every six months. 
In the present study, it was reported that $16 \%$ cure rate (patients were dry (ICIQ-UI SF $=0$ ) at one year which is comparable to 21 percent cure rate in patient treated with laser in randomized controlled trial with follow up only for 3month as reported by (Mija Blaganjea et al 2018). Also, (Tien et al 2017) reported that, 21.9 percent cure rate and 12.5 percent improvement rate based on various questionnaires and scales at 6 months follow-up.

\section{Conclusion}

In majority of patients, stress urinary incontinence may cause psychological distress and have a detrimental effect on their quality of life. In pre- and post-treatment, there was a highly statistically significant gap between baseline (pre-treatment) and post-treatment degrees of SUI daily pads usage.

\section{Recommendations}

Based on the study results, it was recommended that:Psychological intervention should be also used to improve psychological distress and QOL among SUI beside laser therapy.

\section{References}

- El-Azab S, Mohamed M, \& Sabra I, (2007): The prevalence and risk factors of urinary incontinence and its influence on the quality of life among Egyptian women .https://doi.org/10.1002/nau.20412

- Barber MD, Dowsett SA, Mullen KJ, \& Viktrup L. (2005): The impact of stress urinary incontinence on sexual activity in women. Cleve Clin J Med; 72: 225-232.

- Behnia-Willison F, Sarraf S, Miller J, \& Mohamadi B, (2017): Safety and long-term efficacy of fractional $\mathrm{CO} 2$ laser treatment in women suffering from genitourinary syndrome of menopause April. European Journal of Obstetrics, Gynecology, and Reproductive Biology 213 DOI: 10.1016/j.ejogrb.2017.03.036.

- Castro RA, Arruda RM, \& Bortolini MA, (2015): Female urinary incontinence: effective treatment strategies. Climacteric: the journal of the International Menopause Society, 18:135-41.

- Charalambous S, (2009): Impact of urinary incontinence on quality of life. Pelviperineology;28:51-3.

- Dabaja, Lauterbach R, Matanes E, Gruenwald I \& Lowenstein L (2019): The safety and efficacy of $\mathrm{CO} 2$ laser in the treatment of stress urinary incontinence. International Urogynecology Journal volume 31, pages16911696 Cite this article.
- Frani D \& Fistoni I (2019): Laser Therapy in the Treatment of Female Urinary Incontinence and Genitourinary Syndrome of Menopause:; BioMed Research International Article ID 1576359, 9 pages https://doi.org/10.1155/2019/1576359.

- Fultz NH, \& Herzog AR. (2001): Self-reported social and emotional impact of urinary incontinence. J Am Geriatr Soc; 49:892-899.

- Gaspar A, Brandi H, Gomez V, \& Luque D (2016) : Photo-thermal Er: YAG laser treatment of stress urinary incontinence -3 years follow-up. SIU 2016, Buenos Air es, 20-2310. 36th Congress of Société Internationale d'Urologie; 139063.

- Gil K, Somerville A, Cichowski S \& Savitski J (2009): Distress and quality of life characteristics associated with seeking surgical treatment for stress urinary incontinence Health and Quality of Life Outcomes, 7:8 doi:10.1186/1477-7525-7-8

- Gustaf C (2015): Creating a gold standard surgical procedure: the development and implementation of TVT. Int Urogynecol J 2015; 26:467-9.

- Hägglund D, Walker-Engström ML, Larsson G, \& Leppert J. (2004): Changes in urinary incontinence and quality of life after four years. A population-based study of women aged 22-50 years. Scand J Prim Health Care; 22: 112-117.

- Hashim H, Avery K, Mourad MS, Ghoniem G, \& Abrams P, (2006): The Arabic ICIQ-UI SF:an alternative language version of the English ICIQUI SF. Neurourol Urodyn;25:277-282.

- Heidrich SM \& Wells TJ (2004): Effects of urinary incontinence: psychological well-being and distress in older community-dwelling women. J Gerontol Nurs; 30:47-54. [PubMed: 15152744]

- Hillary R. Bogner, Joseph J. Gallo, Mary D. \& Samme 1. (2002): Urinary Incontinence and Psychological Distress in Community-Dwelling Older Adults, JAGS; 50:489-495.

- Hunskaar S., Burgio K., Diokno A., Diokno A, Herzog R, Hjälmås K, \& Lapitan M, (2003): Epidemiology and natural history of urinary incontinence in women, Urology; 62: 16-23.

- Irwin DE, Milsom I, Hunskaar S, Reilly K, Kopp Z, Herschorn S, Coyne K, Kelleher C, HampelC, ,r Artibani W, \& Abrams P (2006): Population-based survey of urinary incontinence, overactive bladder, and other lower urinary tract symptoms in five countries: results of the EPIC study. Eur Urol; 50:1306-1315.

- Kessler RC, Barker PR, Colpe LJ, Epstein JF, Gfroerer JC, Hiripi E, Howes M, Normand T, Manderscheid R, Walters E, \& Zaslavsky A., (2003): Screening for serious mental illness in 
the general population. Arch Gen Psychiatry; 60:184-9.

- Klovning A, Avery K, Sandvik H, \& Hunskaar S.,(2009): Comparison of two questionnaires for assessing the severity of urinary incontinence, the ICIQ-UI SF versus the incontinence severity index, Neurourol Urodyn; 28:411-5.

- Kobachi C, Hsiao K, \& Govier F., (2005): suitability of different sling materials for the treatement of female stress urinary incontenence,Nat Clin Pract Urol ;2:84-91.

- MacLennan AH, Taylor AW, Wilson DH, \& Wilson D (2000): The prevalence of pelvic floor disorders and their relationship to gender, age, parity and mode of delivery. BJOG: an international journal of obstetrics and gynaecology ; 107:1460-70.

- Mija B, Darija Š, Lidija Ž, Ivan V, Franja P \& Adolf L (2018): Non-ablative E: YAG laser therapy effect on stress urinary incontinence related to quality of life and sexual function: A randomized controlled trial. European Journal of Obstetrics \& Gynecology and Reproductive Biology 224, 153-158.

- Norton C, Bhat A, \& Stanton SL (1990): Psychiatric aspects of incontinence in women attending an outpatient urodynamic clinic. BMJ;301:271-2. doi:10.1136/bmj.301.6746.271.

- Novara G., Artibani, W. Barbe M.D. Barber M, Chapple C, Costantini E, Ficarra $V$, Hilton $P$, Nilsson $C, \&$ Waltregny $D$ (2010): Updated systematic review and metaanalysis of the comparative data on colposuspensions, pubovaginal slings, and midurethral tapes in the surgical treatment of female stress urinary incontinence,Eur. Urol. 58 (2) 218-238.

- Ogrinc UB, Senč ar S, Lenasi H(2015)Novel . minimally invasive laser treatment of urinary ;incontinence in women. Lasers Surg Med .47(9)97-689

- Patel \& Thomason (2006): Childbirth and pelvic floor dysfunction: an epidemiologic approach to the assessment of prevention opportunities at delivery, Am. J. Obstet. Gynecol, 195 (1) 23-28

- Perry S, McGrother CW, \& Turner K (2006): An investigation of the relationship between anxiety and depression and urge incontinence in women: development of a psychological model. Br J Health Psychol. 11:463-482. [PubMed: 16870056].

- Pitsouni E , Grigoriadis T, Tsiveleka A Zacharakis D, Salvatore S, HYPERLINK ( 2016): "https://www.maturitas.org/article/S03785122(16)30232-8/fulltext"Microablative fractional CO2-laser therapy and the genitourinary syndrome of menopause: an observationaMaturitas; 94:131s ;94:131-136. doi: 10.1016/j.maturitas.2016.09.012.

- Temml C, Haidinger G, Schmidbauer J, Schatzl G, \& Madersbacher S (2000): Urinary incontinence in both sexes: prevalence rates and impact on quality of life and sexual life. Neurourol Urodyn;19:259-271

- Tennstedt S., Litman H., Zimmern P., Kusek J., Nager C., Mueller E., Kraus S., \& Varner E (2008): The International Urogynecological Association Journal, July PP:1631-1638

- Thomsen S (1991): Pathologic analysis of photo thermal and photomechanical effects of lasertissue interactions. Photochemistry and photobiology; 53(6):825-835.

- Tien YW, Hsiao SM, Lee CN, \& Lin H (2017): Effects of laser procedure for female urodynamic stress incontinence on pad weight, urodynamics, and sexual function. Int Urogynecol J 2017; 28: $469-76$. 